\title{
Safety culture implications on safe work practices and work place exposure incidents in Operation Theater
}

\author{
Tahira Hameed ${ }^{1}$, Eitezaz Ahmed Bashir², \\ Abdul Qadeer Khan ${ }^{3}$, Murtaza Ahmad ${ }^{4}$
}

\begin{abstract}
Background \& Objectives: The study was undertaken to estimate the prevalence of body and blood fluid exposure incidents such as needle stick injuries, direct contact, splashes, and cuts among health care personnel (HCP) in operation theaters (OTs). The study objective was to investigate perception of safety culture and potential challenges faced by HCP in Pakistani context.

Methods: An analytical cross-sectional survey was conducted in four tertiary care hospitals of Rawalpindi and Islamabad that were Akbar Niazi Teaching Hospital (ANTH), Fauji Foundation Hospital (FFH), Benazir Bhutto Hospital (BBH) and Holy Family Hospital (HFH) during March, 2019 to June, 2019. The data of the current study was collected from surgical staff in OTs at four tertiary care teaching hospitals including nurses, house officers, post graduate trainees, registrars, consultants, and technicians in the twin cities i.e., Rawalpindi and Islamabad.

Results: In our findings $(N=367)$ there was a high prevalence of exposure incidents in past six months, $45 \%$ had had got a needle injury, $36 \%$ have got a splash, $28.8 \%$ had direct contact and $35.6 \%$ had a cut once respectively in past six months, the occurrence of exposure incidents twice, thrice and more is also enormous.

Conclusion: The study reflected a dire need of trainings at hospitals so that very strategically the importance of safety being a priority and value of HCP is inculcated on daily basis.
\end{abstract}

KEYWORDS: Culture, Health care, Needle stick injuries, Safety management, Work place.

doi: https://doi.org/10.12669/pjms.37.2.2946

How to cite this:

Hameed T, Bashir EA, Khan AQ, Ahmad M. Safety culture implications on safe work practices and work place exposure incidents in Operation Theater. Pak J Med Sci. 2021;37(2):379-383. doi: https://doi.org/10.12669/pjms.37.2.2946

This is an Open Access article distributed under the terms of the Creative Commons Attribution License (http://creativecommons.org/licenses/by/3.0), which permits unrestricted use, distribution, and reproduction in any medium, provided the original work is properly cited.

1. Dr. Tahira Hameed, MBBS, MRCS. Registrar,

2. Brig. Dr. Eitezaz Ahmed Bashir, FCPS (Surg),

Professor and Head General Surgery,

3. Dr. Abdul Qadeer Khan, MBBS,

Medical Officer, THQ, Murree, Pakistan.

4. Dr. Murtaza Ahmad, MBBS,

Resident Surgery, Sir Ganga Ram Hospital, Lahore, Pakistan.

1, 2: Fauji Foundation Hospital, Rawalpindi, Pakistan.

Correspondence:

Dr. Tahira Hameed, Registrar, General Surgery, Fauji Foundation Hospital,

Rawalpindi, Pakistan.

Email: tahirahameed.th@gmail.com

* Received for Publication:

May 22, 2020

* $1^{\text {st }}$ Revision Received:

* $2^{\text {nd }}$ Revision Received:

* Final Revision Accepted:
June 30,2020

October 19, 2020

October 29, 2020

\section{INTRODUCTION}

In hospitals there are heightened chances for hospital acquired infections majorly because of clinically compromised state of patients admitted; during their stay, care, communication, and treatment; healthcare personnel (HCP) become prone to various communicable diseases and get exposed to biological hazards. ${ }^{1,2} \mathrm{HCP}$ can have occupational accidents in the form of percutaneous and mucocutaneous injury, or blood contact with damaged skin through needles, sharps, splashes of blood and other body fluids into eyes, nose, or mouth. ${ }^{3,4}$ Over 59 million HCP across the globe are prone of getting infected with AIDS, hepatitis, and tuberculosis by accidentally contaminating with patients' blood 
and body fluids. This global issue is overlooked, poorly prevented, and pronounce in developing nations. ${ }^{5}$ Operation theatres (OTs) are the hospital engine room delivering high volume and fast paced procedures. ${ }^{6}$ Safety culture in OTs is intended so that systems, and processes are channeled where potential risk factors are reduced in OTs.

Developing nations like Pakistan face numerous issues such as limited resources and meagre budget to ensure basic health provision and to monitor the biohazards. The surgeons practicing in the system are burdened over un-quantified risk exposure. ${ }^{7}$ The objectives of the study are to estimate the prevalence of exposure incidents in HCP in OTs; to understand perception about safety culture and to explain the challenges faced by HCP in OTs.

\section{METHODS}

After getting ethical approval (Ref. No. FFH/ SURG/15/2019 dated 25 January, 2019) from the concerned hospital authority this analytical cross sectional survey was conducted in four tertiary care hospitals that were Akbar Niazi Teaching Hospital (ANTH) located in Islamabad, Fauji Foundation Hospital (FFH), Benazir Bhutto Hospital (BBH), Holy Family Hospital (HFH) located in Rawalpindi during March, 2019 to June, 2019. A total of 500 respondents were approached for survey. The participants of the study were made aware about the nature of the study and their informed consent was obtained; they were assured that data collected will be kept confidential and used only for research purpose. The data was collected by using convenience sampling technique. The participants were provided with a questionnaire booklet that was designed on the basis of existing literature review and group discussions which incorporated sample demographics Form, questions pertaining prevalence of exposure incidents, probable cause, and incident reporting, the last section of the survey comprised of open ended questions on perception of knowledge on safety culture and challenges in carrying out safer work practices in OTs. The surveys took no longer than 15 minutes to be filled in. The quantitative data was entered and analyzed in IBM SPSS version 23, whereas thematic analysis was carried out on qualitative data.

\section{RESULTS}

Among 500 participants, the response rate was $73 \%$ as 367 participants (males: $n=198$; females: $n=169)$ volunteered to complete the survey Forms with an age range of 21-63 years (Mean $=31 ; S D=$ 3.6). $52.8 \%$ participants were from private sector $n=194$ (ANTH: $n=40$; FFH: $n=154$ ) and $47.1 \%$ were from public sector $n=173$ (BBH: $n=125$; HFH: $n=48)$.

The participants including nurses, house officers, residents, registrar, consultants and OT technicians were $17 \%, 40 \%, 22 \%, 6 \%, 3 \%$ and $12 \%$ respectively. Mostly participants, 117 (31.8\%) had less than 1-year work experience and 132 (35.9\%) had 1-5 years' work experience. When studied working hours per week, mostly 105 (28.6\%) participants had 60-79 hrs./week working hours and $88(24 \%)$ had above $100 \mathrm{hrs}$./week working hours.

\begin{tabular}{|c|c|}
\hline $\begin{array}{l}\text { Perception of safety cultures } \\
\text { - } \quad \text { Availability of resources } \\
\text { - Knowledge about safety } \\
\text { measures } \\
\text { - Adequacy in using PPE } \\
\text { - } \\
\text { - } \\
\text { - } \text { Vacrilizing techniques } \\
\text { - Conducting trainings on } \\
\text { safety culture }\end{array}$ & $\begin{array}{l}\text { Challenges faced by HCP } \\
\text { - Limited resources } \\
\text { - Population explosion } \\
\text { - Time/ workload } \\
\text { - Supportive, mutually } \\
\text { cooperative, high trustworthy } \\
\text { surgical teams } \\
\text { - Good communication flow } \\
\text { among team members } \\
\text { - Fatigue, burnout } \\
\text { - Biomedical waste management }\end{array}$ \\
\hline
\end{tabular}

Fig.1: Conceptual framework regarding perception of safety culture and challenges faced by HCP in OTs. 
Table-I: Relationship between blood, body fluid exposure incidents and work experience ( $\mathrm{N}=367)$.

\begin{tabular}{llccccc}
\hline Variables & 1 & 2 & 3 & 4 & 5 \\
\hline 1 & Working Experience & - & $-0.14^{*}$ & $-0.59^{*+*}$ & $-0.21^{*}$ & $-0.33^{*}$ \\
2 & Needle Stick Injuries & & - & $0.35^{*+}$ & $0.38^{* *}$ & $0.27^{*+}$ \\
3 & Splashes & & & - & $0.52^{*+}$ & $0.25^{*+}$ \\
4 & Direct Contact & & & & - & $0.32^{*+}$ \\
5 & Cuts & & & & - \\
\hline
\end{tabular}

${ }^{*} \mathrm{p} \leq 0.05,{ }^{* *} \mathrm{p} \leq 0.01$.

During last six months, needle stick injuries and splashes were higher $45.5 \%$ and $47 \%$ respectively among HCP. Blood and body fluid exposure multiple times were attributed to factors like stress and long working hours. The incidence of needle stick injuries and cuts twice was $15.5 \%, 16.6 \%$ and $14.4 \%$, and $35.6 \%, 21.9 \%, 15.1 \%$ respectively. The incidence of needle stick injuries and cuts thrice or more declines depicting the positive attitude in efficacy of precautionary measures taken by HCP. Splashes and direct contact basically have a variation in their incidences because splashes occur accidently and direct contacts are also dependent upon the prevalence of the cases in that particular area. There is significant negative relationship between work experience and exposure to blood and body fluids.

Significant positive correlation between working hours and exposure incidents. The more the working hours the more are the chances of exposure incidents as stress makes the HCP not to work effectively. Table-II. This incidence merely is not that simple because increase in work hours indicating negligence and lack of precautionary measures taken which resulted in higher exposure. The more specific factor attributed to this causation is fatigue, cognitive impairment, restlessness and exertion.

\section{DISCUSSION}

Occupational exposure to blood borne diseases is continuing to be a risk factor for hospital staff and surgical staff is even more vulnerable 8-10 On the surgical floor the HCP can contact hospital acquired infections through body and blood fluid exposure incidents, contaminated surfaces, unsterilized instruments, water, air, dust and fomites. ${ }^{11,12}$ HCP working in acute care are more vulnerable to injuries and illnesses. In Pakistani context HCP face challenges as they have inadequate resources, heightened burden of patients, long working hours causing chronic fatigue and burnout. HCP cannot deliver safer care until they feel safe and valued at work place. ${ }^{13}$

Workplace injuries and illnesses cause stress, reduce job satisfaction, and increase turnover intentions. ${ }^{14,15}$ Safety culture can be created by fostering mutual trust among HCP. ${ }^{16}$ Education about the importance of protective equipment and double- glove procedure should be emphasized in healthcare setup so that protocols are established for altering attitude and behaviors in risky environment. ${ }^{9,17}$ Globally legislations and guidelines have paved way in reducing exposure to blood borne pathogens; ${ }^{18}$ but as there are new emerging infectious agents ${ }^{19}$ and minor errors and negligence can result in large consequences. Systematic and targeted efforts in promoting safety and use of personal protective equipment make difference. Dissemination of knowledge through seminars, workshops, and even practical demonstrations about personal protective equipment, the effectiveness of scrubbing,

Table-II: Relationship between blood, body fluid exposure incidents and working hours per week ( $\mathrm{N}=367)$.

\begin{tabular}{llccccc}
\hline Variables & 1 & 2 & 3 & 4 & 5 \\
\hline 1 & Working Experience & - & $0.61^{*+*}$ & $0.38^{*+*}$ & $0.43^{*+*}$ & $0.36^{*+*}$ \\
2 & Needle Stick Injuries & & - & $0.35^{+*}$ & $0.38^{*+*}$ & $0.27^{*+*}$ \\
3 & Splashes & & - & $0.52^{*+}$ & $0.25^{* *}$ \\
4 & Direct Contact & & & - & $0.32^{*+*}$ \\
5 & Cuts & & & & - \\
\hline
\end{tabular}

${ }^{* *} \mathrm{p} \leq 0.01$. 


\section{Needle Stick Injuries}

\section{Splashes}

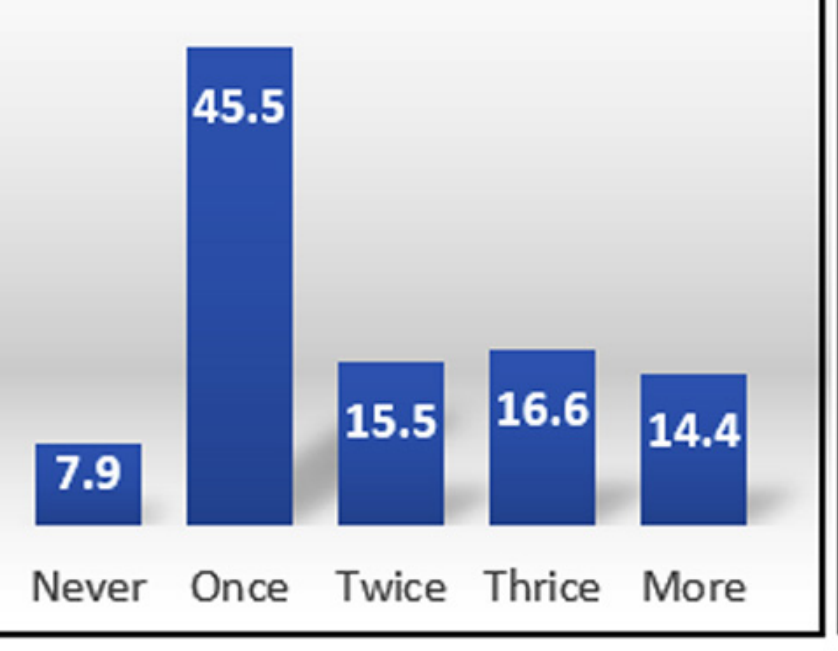

\section{Direct Contact}

\section{Cuts}

NeverOnce TwiceThriceMore
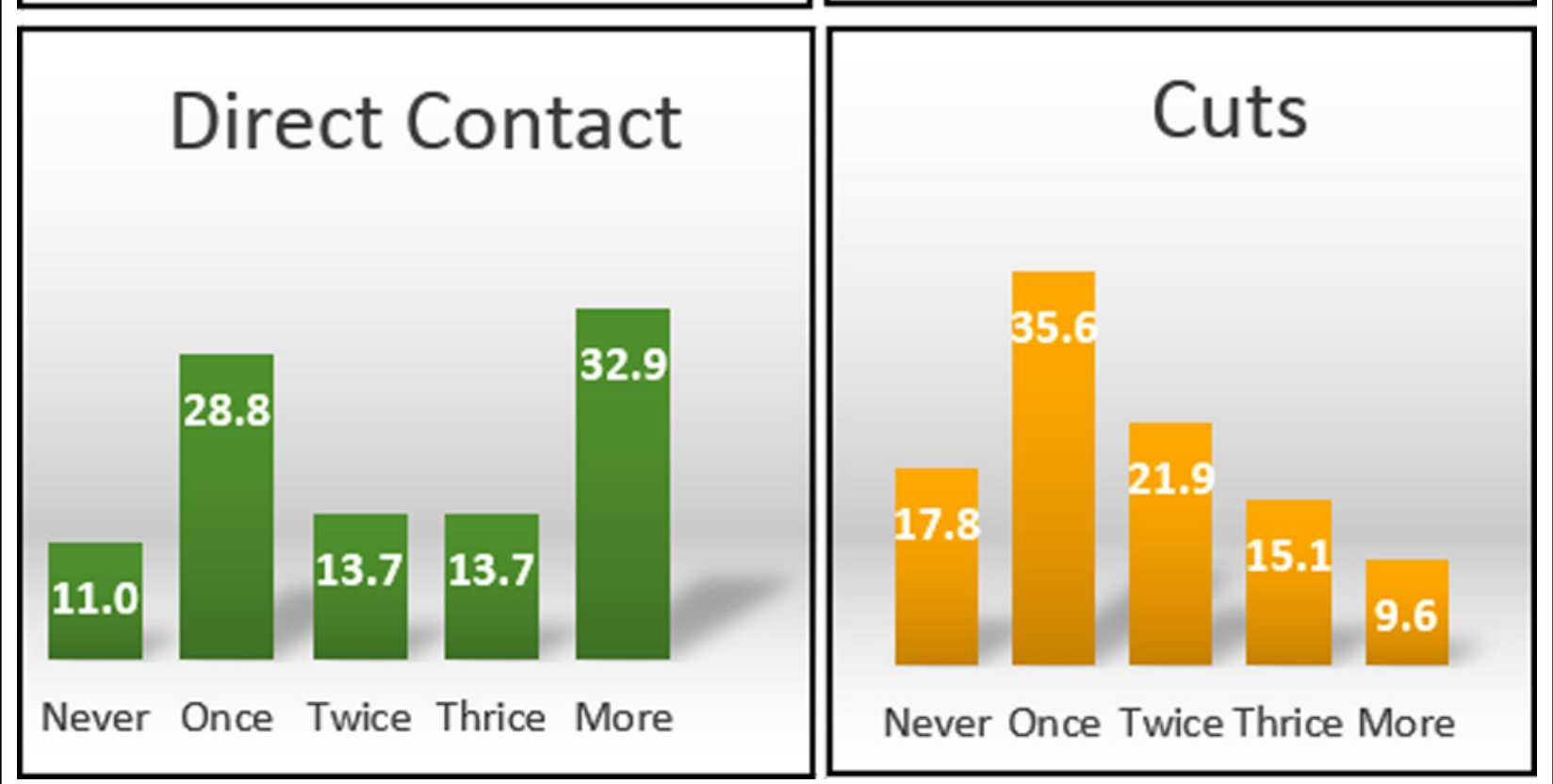

Graph.1: Prevalence of blood, body fluid exposure incidents percentages in $\mathrm{HCP}$ in past six months (N=367).

disinfection, cleaning, aerosolizing of OTs and the OT staff is highly relevant and valid. New methodologies for training of HCP like simulation training and teamwork training appears to be critical for house officers, trainees, registrars, surgeons and all OT staff. We aim to provide training on non-technical levels as well such as communication, teamwork, leadership and decision making that is mandatory in providing optimal health care set up with minimal exposure to bio hazards.
Limitations of the study: It was a cross sectional study that limits answering cause and effect relationships; the data of the study was collected from twin cities of Pakistan therefore limiting the generalizability to rural and small healthcare settings. This study has highlighted the existing problems and challenges faced by the healthcare workers so the various stakeholders need to take measures to overcome the problems. 


\section{CONCLUSION}

The current study has highlighted the significance of safety culture as the core value of healthcare sector, the hospital employees when are unaware of efficacy of use of personal protective equipment, have less knowledge of safety culture and dire importance of taking precautionary measures, scrubbing, disinfection, and hygiene of operation theaters, they are more prone to illness, infection, and disease within the staff and cross to the patients as well. So, in Pakistani setup there is need for regulation of work hours and inculcation of safety as integral part of curriculum and practice. When healthcare personnel feel safe and secure, they can ensure sound health delivery with maximum output.

\section{Grant Support \& Financial Disclosures: None.}

\section{REFERENCES}

1. Baker A. Crossing the quality chasm: a new health system for the 21st century. BMJ. 2001;323(7322):1192. doi: 10.1136/bmj.323.7322.1192

2. Alam AY. Implementing evidenced based patient safety practices. J Pak Med Assoc. 2016;66(6):637-638.

3. Rapisarda V, Loreto C, Vitale E, Matera S, Ragusa R, Coco $\mathrm{G}$, et al. Incidence of sharp and needle-stick injuries and mucocutaneous blood exposure among healthcare workers. Future Microbiol. 2019;14(9s):27-31. doi: 10.2217/ fmb-2018-0239

4. World Health Organization. Aide-memoire for a strategy to protect health workers from infection with blood borne viruses. 2003. WHO/EHT/03.11.

5. Mandic B, Mandic-Rajcevic S, Markovic-Denic L, Bulat P. Occupational exposure to blood and bodily fluids among healthcare workers in Serbian general hospitals. Arh Hig Rada Toksikol. 2018;69(1):61-68. doi: 10.2478/ aiht-2018-69-3047

6. Scott D, Shafi M. The WHO surgical checklist: Improving safety in our operating theatres. Obstet Gynaecol Reprod Med. 2018;28(9):295-297. doi: 10.1016/j.ogrm.2018.08.002

7. Younis MU, Shah SF, Muzafar A, Sarwar MZ, Rehman F, Hameed S. Needle stick injury reporting among surgeons in tertiary hospitals of Lahore. Prof Med J. 2019;26(06):907912. doi: 10.29309/TPMJ/2019.26.06.3593

8. Van Buijtene A, Foster D. Does a hospital culture influence adherence to infection prevention and control and rates of healthcare associated infection? A literature review. J Infect Prev. 2019;20(1):5-17. doi: 10.1177/1757177418805833

9. Hasak JM, Novak CB, Patterson JM, Mackinnon SE. Prevalence of needle stick injuries, attitude changes, and prevention practices over 12 years in an urban academic hospital surgery department. Ann Surg. 2018;267(2):291 296. doi: $10.1097 /$ SLA.0000000000002178

10. Makary MA, Al-Attar A, Holzmueller CG, Sexton JB, Syin $\mathrm{D}$, Gilson MM et al. Needle sticks injuries among surgeons in training. N Engl J Med. 2007;356(26):2693-2699. doi: 10.1056/NEJMoa070378
11. Joshi SC, Diwan V, Joshi R, Sharma M, Pathak A, Shah H et al. "How Can the Patients Remain Safe, If We Are Not Safe and Protected from the Infections"? A Qualitative Exploration among Health-Care Workers about Challenges of Maintaining Hospital Cleanliness in a Resource Limited Tertiary Setting in Rural India. Int J Env Res Pub He. 2018; 15(9):1942. doi: 10.3390/ijerph15091942

12. Dancer SJ. Hospital cleaning in the 21st century. Eur J Clin Microbiol Infect. Dis. 2011;30(12):1473-1481. doi: 10.1007/ s10096-011-1250-x

13. Lucian Leape Institute National Patient Safety Foundation. Through the Eyes of the Workforce: Creating Joy, Meaning and Safer Health Care. National Patient Safety Foundation; 2013.

14. McCaughey D, Delli Fraine JL, McGhan G, Bruning NS. The negative effects of workplace injury and illness on workplace safety climate perceptions and health care worker outcomes. Saf Sci. 2013;51(1):138-147. doi: 10.1016/j.ssci.2012.06.004

15. McCaughey D, Delli Fraine J, Erwin CO. Best practices to promote occupational safety and satisfaction: A comparison of three North American hospitals. In International Best Practices in Health Care Management 2015: 137-159. Emerald Group Publishing Limited. doi: 10.1108/S1474823120140000017008

16. Groves PS. The relationship between safety culture and patient outcomes: Results from pilot meta-analyses. West J Nurs Res. 2014;36(1):66-83. doi: 10.1177/0193945913490080

17. Makary MA, Pronovost PJ, Weiss ES, Millman EA, Chang D, Baker SP, et al. Sharp less surgery: a prospective study of the feasibility of performing operations using non-sharp techniques in an urban, university-based surgical practice. World J Surg. 2006;30(7):1224-1229. doi: 10.1007/s00268005-0605-9

18. Kuhar D, Pollock D, Yokoe D, Howell M, Chopra V. Healthcare infection control practices advisory committee (HICPAC). 2018.

19. Boggild AK, Libman M, Greenaway C, McCarthy AE, Committee to Advise on Tropical Medicine. Emerging infectious diseases: CATMAT statement on disseminated strongyloidiasis: Prevention, assessment and management guidelines. Can Commun Dis Rep. 2016;42(1):12. doi: 10.14745/ccdr.v42i01a03

\section{Author`s Contribution:}

TH provided concept/research design and did data collection, subjects \& editing of manuscript.

AQK and MA did statistical analysis and manuscript writing.

TH and EAB did editing of manuscript and project management.

TH did data collection, subjects and provision of facilities/equipment.

TH takes the responsibility and is accountable for all aspects of the work in ensuring that questions related to the accuracy or integrity of any part of the work are appropriately investigated and resolved. 